EDITORIALS

\title{
Infantile Onset Diabetes Mellitus
}

\author{
INDER PAL Singh Kochar \\ Apollo Hospital, Sarita Vihar,Delhi, India. inderpal_kochar@yahoo.com
}

$\mathrm{D}$ iabetes mellitus is an etiologically heterogeneous disorder. Monogenic forms of diabetes mellitus cover a heterogeneous group of diabetes which are uniformly caused by a single gene mutation and are characterized by impaired insulin secretion of the pancreatic beta cell. It is estimated that they account for up to $5 \%$ of all cases of diabetes mellitus, which are often not diagnosed or are misclassified as type 1 or 2 diabetes. However, accurate diagnosis is important because of the special implications for treatment, prognosis and family risk. The knowledge of typical clinical features such as mode of inheritance, age at diagnosis and impaired insulin secretion, as well as genetic testing establishes the diagnosis of MODY, mitochondrial diabetes and neonatal diabetes. In particular, diabetes occurring under 6 months of age - usually termed neonatal diabetes - appears to be predominantly monogenic.

The neonatal diabetes phenotype encapsulates numerous subtypes, wherein most etiologies involve a severe disruption in $\beta$-cell function. Neonatal diabetes can be permanent and require lifelong treatment, or may be transient, in which case the diabetes may spontaneously remit (or be so mild as not to require treatment), but will often relapse, usually during adolescence. Nearly half of all cases of permanent neonatal diabetes are due to activating mutations in $K C N J 11$ or $A B C C 8$; their diabetes can be remarkably well controlled by oral sulfonylurea instead of injected insulin $[1,2]$. In most such cases, transition from insulin to sulfonylurea therapy is best done during an inpatient admission using published guidelines [2], with advice sought from recognized centers with extensive experience. Although the resulting treatment is clearly easier and the level of diabetes control better, many questions still remain to be clarified:

1. How sustainable will the treatment with oral sulfonylureas be, and will age, obesity, or other factors eventually require supplemental insulin or other medications? In this regard, a single case has been fortuitously treated for over 50 years [1]. Furthermore, literature reports $[3,4]$ all continue to do well and give reason for optimism, but only time and careful tracking of long-term outcome will tell.

2. How often will patients have hypoglycemia, and what happens to their blood sugar levels during illness, procedures, or hospitalization, especially if oral medications cannot be taken?

3. To what extent will neurodevelopmental effects be improved or even prevented by sulfonylurea treatment? In this regard a notable study recently confirmed that mice with brain expression of a mutant form of the protein encoded by KCNJ11 (Kir6.2) have a neurologic phenotype reminiscent of patients with the same mutation (V59M) [5].

In this issue, Varadarajan, et al. [6] report a series of 40 cases with infantile onset diabetes mellitus (IODM) and their long-term follow up which is the first in our country. The study lucidly highlights the issue of IODM and the paucity of its recognition. More so, it highlights the need for genetic evaluation in this select group of diagnosis. We expect that within a few years, important breakthroughs will be made in mapping cases of diabetes with a suspected, but still unsolved monogenic basis.

Competing interest: None stated; Funding: Nil.

\section{REFERENCES}

1. Gloyn AL, Pearson ER, Antcliff JF, Proks P, Bruining GJ, Slingerland AS, et al. Activating mutations in the gene encoding the ATP-sensitive potassium-channel subunit Kir6.2 and permanent neonatal diabetes. N Engl J Med. 2004;350:1838-49.

2. Pearson ER, Flechtner I, Njølstad PR, Malecki MT, Flanagan SE, Larkin B, et al. Switching from insulin to oral sulfonylureas in patients with diabetes due to Kir6.2 mutations. N Engl J Med. 2006;355:467-77.

3. Stoy J, Greeley SAW, Paz VP, Ye H, Pastore AN, Skowron $\mathrm{KB}$, et al. Diagnosis and treatment of neonatal diabetes: a United States experience. Pediatr Diabetes. 2008;9:450-9.

4. Iafusco D, Bizzarri C, Cadario F, Pesavento R, Tonini G, Tumini $\mathrm{S}$, et al. No beta cell desensitisation after a median of 68 months on glibenclamide therapy in patients with KCNJ11-associated permanent neonatal diabetes. Diabetologia. 2011;54:2736-8.

5. Clark RH, McTaggart JS, Webster R, Mannikko R, Iberl M, Sim XL, et al. Muscle dysfunction caused by a KATP channel mutation in neonatal diabetes is neuronal in origin. Science. 2010;329:458-61.

6. Varadarajan P, Sangaralingam T, Senniappan S, Jahnavi S, Radha V, Mohan V. Clinical presentation and long term outcome of 40 children with infantile onset diabetes mellitus in South India. Indian Pediatr. 2013;50:759-63. 